\title{
Vinyl Polymerization by Copper (I) tert-Butoxide
}

\author{
Takeo SAegusa, Sadashige Horiguchi, and Tetsuo Tsuda \\ Department of Synthetic Chemistry, Faculty of Engineering, \\ Kyoto University, Kyoto 606, Japan.
}

(Received January 14, 1976)

\begin{abstract}
This paper describes the catalyst character of copper (I) tert-butoxide $(t-\mathrm{BuOCu})$ for vinyl polymerization. At the low temperature of $0^{\circ} \mathrm{C}, t-\mathrm{BuOCu}$ initiated the anionic polymerization of acrylonitrile (AN) in the presence of a coordinating compound such as tert-butyl isocyanide $(t$-BuNC), trimethyl phosphite, triphenylphosphine, and hexamethylphosphoric triamide (HMPT). The mechanism of the anionic polymerization was shown by the reaction of $\mathrm{AN}$ monomer with $t$-BuOCu$-t-\mathrm{BuNC}$ in the presence of a protic solvent of tert-BuOH and by copolymerization experiments. Without any coordinating compound, $t$-BuOCu caused the polymerization of styrene (ST), methyl acrylate (MA), methyl methacrylate (MMA), and AN at the higher temperature of $80^{\circ} \mathrm{C}$, where a radical mechanism was assumed.

KEY WORDS Vinyl Polymerization / $t$-BuOCu / Ligand / Anionic Mechanism / Organocopper / Acrylonitrile / $t$-BuNC / Phosphine / HMPT / Copolymerization /
\end{abstract}

In a previous paper, ${ }^{1}$ vinyl polymerization by the cyclopentadienylcopper (I)-tert-butyl isocyanide complex ((CPD)Cu. $t$-BuNC) was reported. This complex alone did not induce the polymerization, but became highly effective for the polymerization when excess $t$-BuNC was added. In this polymerization, the organocopper (I) complex was assumed to be the propagating species. The results of both homopolymerization and copolymerization by $(\mathrm{CPD}) \mathrm{Cu} \cdot(t-\mathrm{BuNC})_{2}$ were different from those of the conventional anionic polymerizations by the catalysts of organolithium and organomagnesium.

This paper describes the vinyl polymerization by $t$-BuOCu. $t$-BuOCu is one of the very few examples of thermally stable copper (I) alkoxides which has been found to be an efficient reagent of metalation (organocopper formation). ${ }^{2}$

\section{RESULTS AND DISCUSSION}

Vinyl Polymerization by $t-\mathrm{BuOCu}$

$t$-BuOCu was prepared from the reaction of tert-BuOLi with $\mathrm{CuCl}$, which was purified by sublimation. ${ }^{2}$ At $0^{\circ} \mathrm{C}, t$-BuOCu alone did not induce the vinyl polymerization, but $\mathrm{AN}$ was polymerized when $t$-BuNC was added to $t$-BuOCu. Table I shows the effect of added $t$-BuNC on the conversion and molecular weight of the product polymer. About an equimolar amount of $t$-BuNC to $t-\mathrm{BuOCu}$ was required to activate $t-\mathrm{BuOCu}$. Larger excess of $t$-BuNC did not much affect either the conversion or the molecular weight of the product polymer. Under the present experimental conditions, the best conversion was obtained when the ratio of $t-\mathrm{BuNC}$ to $t-\mathrm{BuOCu}$ was 2 . As for the vinyl polymerization by the system of $t$-BuOCu$-t$-BuNC, it should be mentioned that an isolated species of $t$-BuOCu.tBuNC complex, which was prepared from an equimolar mixture of $t$-BuOCu and $t$-BuNC, has

Table I. Effect of $t$-BuNC on polymerization of $\mathrm{AN}^{\mathrm{a}}$

\begin{tabular}{ccc}
\hline$t$-BuNC/t-BuOCu & Conv., $\%$ & Polymer, mol wt \\
\hline 0 & 0 & - \\
0.1 & 0.4 & - \\
0.2 & 1.5 & - \\
0.5 & 9.4 & 2590 \\
1.0 & 61.8 & 4450 \\
2.0 & 66.6 & 3910 \\
5.0 & 57.5 & 4870 \\
10.0 & 48.6 & 4170 \\
\hline
\end{tabular}

a $t$-BuOCu, $0.20 \mathrm{mmol}$; AN, $76 \mathrm{mmol}$; toluene, 10.0 $\mathrm{m} l$; polymerization at $0^{\circ} \mathrm{C}$ for $3 \mathrm{hr}$. 
Table II. Polymerization of AN by $t-\mathrm{BuOCu}$ and coordinating compound ${ }^{a}$

\begin{tabular}{lcc}
\hline \multicolumn{1}{c}{ Additive } & Conv., $\%$ & Polymer, mol wt \\
\hline$t$-BuNC & 57.4 & 3320 \\
$\mathrm{P}\left(\mathrm{OCH}_{3}\right)_{3}$ & 41.1 & 1890 \\
$\mathrm{HMPT}$ & 22.7 & 5560 \\
$\mathrm{PPh}_{3}$ & 13.5 & 3080 \\
Dipy & 8.9 & 6110 \\
TMEDA & 3.8 & 1020 \\
THF & 0.4 & - \\
Quinoline & 0.4 & - \\
\hline
\end{tabular}

a $t$-BuOCu, $0.20 \mathrm{mmol}$; Additive (coordinating compound), $0.20 \mathrm{mmol}$; AN, $76 \mathrm{mmol}$; toluene, $5.0 \mathrm{ml}$; polymerization at $0^{\circ} \mathrm{C}$ for $3 \mathrm{hr}$.

been shown to induce the metalation of various organic compounds. ${ }^{3}$ In the present study, an isolated species of $t$-BuOCu$\cdot t$-BuNC complex also initiated the polymerization of AN.

Some other coordinating compounds were found to activate $t$-BuOCu in the polymerization of AN (Table II). Trimethyl phosphite, HMPT, and triphenylphosphine were quite effective, while $\alpha, \alpha^{\prime}$-dipyridyl (Dipy) and $N, N, N^{\prime}, N^{\prime}$-tetramethylethylenediamine (TMEDA) were less effective. Other vinyl monomers, MA, MMA, and ST, were not polymerized under these polymerization conditions by the catalyst system of $t$ $\mathrm{BuOCu}$ with $t$-BuNC or with other coordinating compounds.

The mode of the initiation reaction may be assumed to be the nucleophilic addition of $t$ $\mathrm{BuOCu}$ to $\mathrm{AN}$ to produce organocopper (I), which functions as a real initiating species. The effect of the addition of a coordinating compound may be ascribed to the dissociation of the polymeric structure of $t$-BuOCu and the increase of the nucleophilic reactivity of the tert-butoxyl group of the initiator. The dissociation of the polymeric $t$-BuOCu by $t$-BuNC has been demonstrated by the dissolution of $t-\mathrm{BuOCu}$ in organic solvents in the presence of $t$-BuNC ${ }^{3}$. $t$-BuNC and phosphite were quite effective, while THF and quinoline were much less effective, for the activation of $t$-BuOCu. This result can be explained in terms of the concept of the soft and hard natures of the ligands which control the reactivity and the stability of copper (I) complexes. ${ }^{4}$

The proposal of initiation through the nucleophilic addition of tert-butoxyl group to AN was supported by the experiment of the polymerization in the presence of tert-BuOH, in which $\beta$-tertbutoxypropionitrile was obtained in a 5.0-\% yield together with $51 \%$ of polyacrylonitrile (eq 1 ). The formation of the third product of the dimer of AN, $\alpha$-methylene glutaronitrile, may be explained by the formation of vinylcopper (I) intermediate by the abstraction of the hydrogen of $\mathrm{AN}$, i.e., the direct metalation of $\mathrm{AN}$ monomer by $t$-BuOCu- $t$-BuNC (eq 2) and/or the chaintransfer reaction of hydrogen transfer from AN monomer to the propagating end (eq 3 ).

$$
\begin{aligned}
& \begin{array}{r}
\mathrm{CH}_{2}=\mathrm{CHCN}+t \text {-BuOCu} \cdot \mathrm{L} \underset{\mathrm{L}=t \text { - } \mathrm{BuNC} t-\mathrm{BuOH}, \mathrm{THF}}{0^{\circ} \mathrm{C}, 5 \mathrm{hr}} \\
\longrightarrow
\end{array}
\end{aligned}
$$

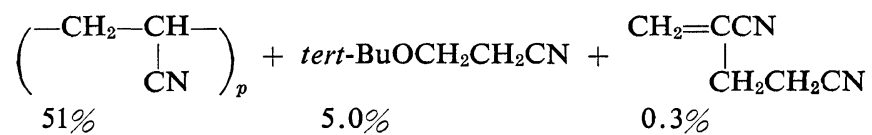

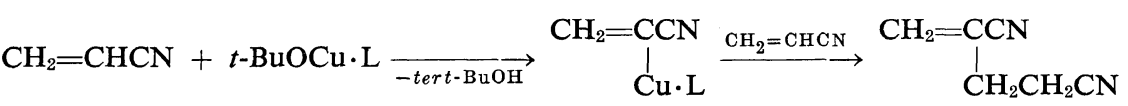

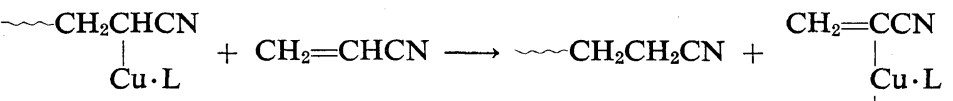

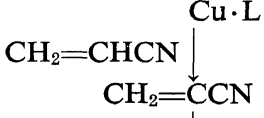

$$
\begin{aligned}
& \mathrm{CH}_{2} \mathrm{CH}_{2} \mathrm{CN}
\end{aligned}
$$

$t$ - $\mathrm{BuOCu}-t$-BuNC did not induce the polymerization of MMA, whereas (CPD) $\mathrm{Cu}(t-\mathrm{BuNC})_{2}$ did initiate the polymerization. This difference may be attributed to the decreased nucleophilic reactivity of the copper-alkoxyl bond compared with that of the copper-alkyl bond. It is inter- 
esting to make a comparison of the reactivity between copper (I) complexes and lithium reagents for the initiation of vinyl polymerization. Alkyllithium is known to cause the anionic polymerizations of ST and other electrophilic vinyl monomers, and $t$-BuOLi can initiate the polymerization of MMA but not of ST. ${ }^{5}$ On the other hand, an alkylcopper complex, e.g., $(\mathrm{CPD}) \mathrm{Cu}(t-\mathrm{BuNC})_{2}$ can initiate the anionic polymerization of MMA, and $t$-BuOCu$-t$-BuNC initiates that of AN but not of MMA. The difference may be explained by the lower nucleophilic reactivity of copper (I) complexes compared with that of the corresponding lithium reagents. ${ }^{6}$ Methylcopper tricyclohexylphosphine complex has been reported to polymerize AN and MMA but not ST, which agrees with the results of the polymerization by $(\mathrm{CPD}) \mathrm{Cu}(t-\mathrm{BuNC})_{2}{ }^{7}$

Table III. Polymerization of vinyl monomers by $t-\mathrm{BuOCu}$ at $80^{\circ} \mathrm{C}^{\mathrm{a}}$

\begin{tabular}{lcc}
\hline Monomer & Conv., $\%$ & Polymer, mol wt \\
\hline ST & 13.9 & 22000 \\
MA & 13.6 & 21400 \\
MMA & 9.2 & 23400 \\
AN & 4.7 & 1180 \\
MAN & 0.2 & - \\
\hline
\end{tabular}

a $t$-BuOCu, $0.20 \mathrm{mmol}$; monomer, $5.0 \mathrm{ml}$; toluene, $5.0 \mathrm{ml}$; polymerization was carried out for $16 \mathrm{hr}$.

Without a coordinating compound, $t$ - $\mathrm{BuOCu}$ induced vinyl polymerization at the higher temperature of $80^{\circ} \mathrm{C}$ (Table III). The conversion was relatively low. Here ST was polymerized by $t$-BuOCu. These observations may be taken to suggest a mechanism of radical polymerization. ${ }^{8}$

\section{Vinyl Copolymerization by $\mathrm{t}-\mathrm{BuOCu}$}

The character of $t$-BuOCu as a polymerization catalyst was examined also in copolymerization at $0^{\circ} \mathrm{C}$. Figures 1,2 , and 3 show the copolymer composition curves of the copolymerizations of AN with MA, MMA, and ST, respectively. In every case, the rate of polymerization decreased as the molar fraction of AN monomer decreased. In the copolymerization with MA (Figure 1), the AN content in the copolymer exceeds that of MA. This is a clear indication of an anionic polymerization. ${ }^{9}$ More interesting is the fact

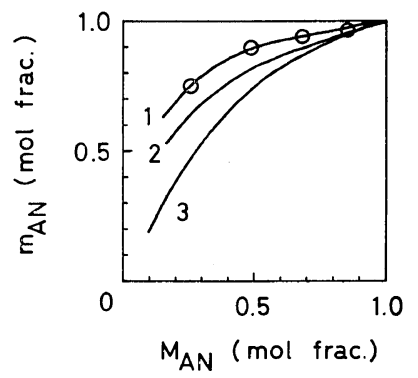

Figure 1. Copolymerization curves for AN-MA: (1), $t$-BuOCu$-t$-BuNC, in toluene at $0^{\circ} \mathrm{C}$; (2), $\mathrm{Cu}_{2} \mathrm{O}-t-\mathrm{BuNC}$, at $80^{\circ} \mathrm{C}^{12}(3), n-\mathrm{BuLi}$, in benzene at $0^{\circ} \mathrm{C} .13$

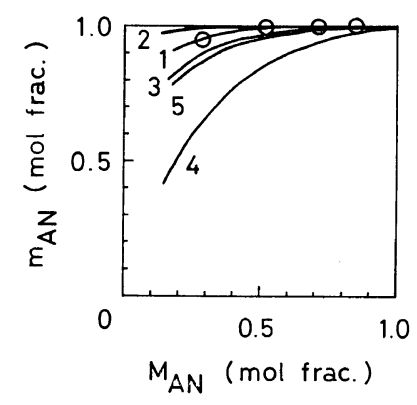

Figure 2. Copolymerization curves for $\mathrm{AN}-$ MMA: (1), $t$-BuOCu$-t$-BuNC, in toluene at $0^{\circ} \mathrm{C}$; (2), (CPD) $\mathrm{Cu}(t-\mathrm{BuNC})_{2}$, in $\mathrm{DMF}$ at $-78^{\circ} \mathrm{C} ;^{1}$ (3), $\mathrm{Cu}_{2} \mathrm{O}-t$-BuNC, at $80^{\circ} \mathrm{C} ;{ }^{12}$ (4), $n$-BuLi, bulk at $-8^{\circ} \mathrm{C} ;{ }^{13}(5), \mathrm{PhMgBr}$, in toluene at $-70^{\circ} \mathrm{C} .11$

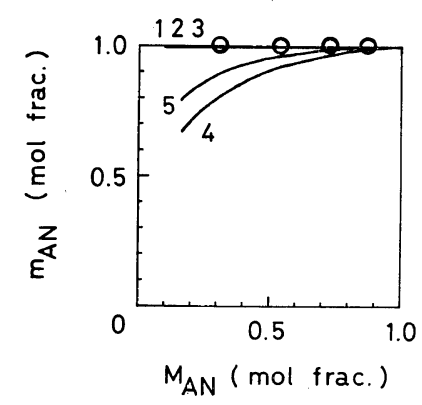

Figure 3. Copolymerization curves for $\mathrm{AN}-\mathrm{ST}$ : (1), $t$ - $\mathrm{BuOCu}-t-\mathrm{BuNC}$, in toluene at $0^{\circ} \mathrm{C}$; (2), (CPD) $\mathrm{Cu}(t-\mathrm{BuNC})_{2}$, in DMF at $0^{\circ} \mathrm{C} ;{ }^{1}(3), \mathrm{Cu}_{2} \mathrm{O}-$ $t$-BuNC, at $80^{\circ} \mathrm{C} ;{ }^{12}(4), n$-BuLi, in ether at $-12^{\circ} \mathrm{C} ; 1^{13}$ (5), $\mathrm{PhMgBr}$, in toluene-ether at $-70-0^{\circ} \mathrm{C} .1^{11}$

that the AN content of the copolymer by $t$ $\mathrm{BuOCu}-t$-BuNC (curve 1) is much higher than that by $n$-BuLi (curve 3 ). This difference may be due to the specific coordination of AN onto 
copper. The specific enhanced reactivity of AN was also observed in the case of the binary catalyst system of $\mathrm{Cu}_{2} \mathrm{O}$ and $t$-BuNC (curve 2). The difference between curve 1 and 2 may be ascribed to the differences of the polymerization conditions.

In the copolymerization with MMA (Figure 2), the AN unit was exclusively incorporated into the copolymer except at low molar fraction of AN monomer. Furthermore, in the copolymerization with ST (Figure 3), the presence of an ST unit was not detected in the NMR spectra of the product polymer. As to the polymerization of ST by organometallic catalyst, the results with a catalyst of a Grignard reagent are to be mentioned here. Though ST was not homopolymerized by a Grignard reagent alone, ${ }^{10}$ it was copolymerized with AN by the same catalyst. ${ }^{11}$ The coordination of AN onto magnesium may activate the Grignard reagent catalyst. In the present study, however, organocopper (I) complex induced neither the anionic homopolymerization nor the anionic copolymerization of ST.

\section{EXPERIMENTAL}

\section{Reagents}

$t$-BuOCu was prepared and isolated as previously reported, ${ }^{2}$ and was dissolved in toluene to a $0.04 \mathrm{M} / \mathrm{L}$ solution. This solution was stored without decomposition under nitrogen at ambient temperature. $t$-BuNC was prepared by the dehydration of $\mathrm{N}$-tert-butyl formamide with $\mathrm{POCl}_{3}{ }^{14}$ Monomers, solvents, and other reagents were all commercial reagents and were purified by the usual methods.

\section{Polymerization Procedures}

Typical polymerization procedures were as follows: monomer and solvent were placed in a test tube under nitrogen, and then a solution of $t$-BuOCu (and coordinating compound) in toluene was added. After polymerization the polymer solution was poured into a mixture of $\mathrm{CH}_{3} \mathrm{OH}$ and a small amount of aqueous $\mathrm{HCl}$. The precipitated polymer was isolated by filtration, washed with $\mathrm{CH}_{3} \mathrm{OH}$, and dried in vacuo. Molecular weight was determined in DMF by means of a Hitachi Perkin-Elmer 115 vaporpressure osmometer. In copolymerization ex- periments, the conversion was below $10 \%$. The composition of the copolymer was determined by a Hitachi $60-\mathrm{MHz}$ R-20B NMR spectrometer in $d_{6}$-dimethyl sulfoxide solution. ${ }^{1,12}$

The polymerization of $\mathrm{AN}$ in the presence of a protic solvent was carried out as follows: To a mixture of $0.26 \mathrm{~g}(1.90 \mathrm{mmol})$ of $t-\mathrm{BuOCu}$, $0.21 \mathrm{~m} l(1.90 \mathrm{mmol})$ of $t$-BuNC, and $9.0 \mathrm{~m} l$ of tert-BuOH in $20.0 \mathrm{~m} l$ of THF, $6.24 \mathrm{ml}(95 \mathrm{mmol})$ of AN was added dropwise at $0^{\circ} \mathrm{C}$. After the reaction mixture was stirred at $0^{\circ} \mathrm{C}$ for $5 \mathrm{hr}$, it was poured into a large amount of $\mathrm{CH}_{3} \mathrm{OH}$ containing a small amount of aqueous $\mathrm{HCl}$. The insoluble polymer of AN was isolated by filtration, washed by $\mathrm{CH}_{3} \mathrm{OH}$, and dried in vacuo. The yield of polymer was $51 \%$. The methanol solution was concentrated and subjected to glpc analysis. $\beta$-tert-Butoxypropionitrile $(5.0 \%)$ and $\alpha$-methylene glutaronitrile $(0.3 \%)$ were isolated by preparative glpc and identified: $\beta$-tert-butoxypropionitrile: IR (neat), $2250\left(\nu_{\mathrm{C} \equiv \mathrm{N}}\right)$ and 1095 $\mathrm{cm}^{-1}\left(\nu_{\mathrm{C}-\mathrm{O}}\right)$; NMR (in $\left.\mathrm{CDCl}_{3}\right), \tau 6.46(\mathrm{t}, J=6.0$ $\left.\mathrm{Hz}, 2 \mathrm{H}, \mathrm{O}-\mathrm{CH}_{2}\right), 7.51$ (t, $J=6.0 \mathrm{~Hz}, 2 \mathrm{H}-$ $\mathrm{CH}_{2} \mathrm{CN}$ ), and 8.80 (s, 9H, $\left(\mathrm{CH}_{3}\right)_{3} \mathrm{C}-$-) mass, parent $m / e=127$ (calcd for $\mathrm{C}_{7} \mathrm{H}_{13} \mathrm{ON}, 127.2$ ). $\alpha$ methylene glutaronitrile: IR (neat), 2245 and $2220\left(\nu_{\mathrm{C} \equiv \mathrm{N}}\right), 1624\left(\nu_{\mathrm{C}=\mathrm{C}}\right)$, and $955 \mathrm{~cm}^{-1}\left(\delta_{=\mathrm{C}-\mathrm{H}}\right)$; NMR (in $\mathrm{CDCl}_{3}$ ), $\tau 4.00$ (s, $1 \mathrm{H}, \mathrm{CH}=$ ), 4.11 (s, $1 \mathrm{H}, \mathrm{CH}=$ ), and 7.39 (s, $\left.4 \mathrm{H},-\mathrm{CH}_{2} \mathrm{CH}_{2}-\right)$; mass, parent $m / e=106$ (Calcd for $\mathrm{C}_{6} \mathrm{H}_{6} \mathrm{~N}_{2}, 106.1$ ).

\section{REFERENCES}

1. T. Saegusa, S. Horiguchi, and T. Tsuda, Macromolecules, 8, 112 (1975).

2. T. Tsuda, T. Hashimoto, and T. Saegusa, $J$. Amer. Chem. Soc., 94, 658 (1972).

3. T. Tsuda, H. Habu, S. Horiguchi, and T. Saegusa, ibid., 96, 5930 (1974).

4. R. G. Pearson, ibid., 85, 3533 (1963), Science, 151, 172 (1966).

5. J. Trekoval and D. Lim, J. Polym. Sci. Part C, 4, 333 (1964).

6. J. F. Normant, Synthesis, 1972, 63.

7. T. Ikariya, and A. Yamamoto, J. Organometal. Chem., 72, 145 (1974).

8. S. Inoue, "Structure and Mechanism in Vinyl Polymerization", T. Tsuruta, Ed., Marcel Dekker, New York, N.Y., 1969, p 125.

9. The monomer reactivity ratios for the radical copolymerization: $\gamma_{\mathrm{AN}}=1.5, \gamma_{\mathrm{MA}}=0.84$ (by BPO at $60^{\circ} \mathrm{C}$ ). C.S. Marvel and R. Schwen, $J$. 
T. SAegusa, S. Horiguchi, and T. Tsuda

Amer. Chem. Soc., 79, 6003 (1957).

10. M. Tomoi and H. Kakiuchi, Kogyo Kagaku Zasshi (J. Chem. Soc. Japan, Ind. Chem. Sect.), 73, 2367 (1970). A Grignard reagent-coordinating compound system polymerizes ST.

11. F. Dawans and G. Smets, Makromol. Chem.,
59, 163 (1963).

12. T. Saegusa and S. Horiguchi, Polymer J., 6, 419 (1974).

13. N. L. Zutty and F. J. Welch, J. Polym. Sci., 43, 445 (1960).

14. I. Ugi and R. Meyr, Chem. Ber., 93, 239 (1960). 